\title{
Prevalence and Characteristics of Ever Regular Use of Non-combustible Nicotine for One-year or More: A Population Survey in England
}

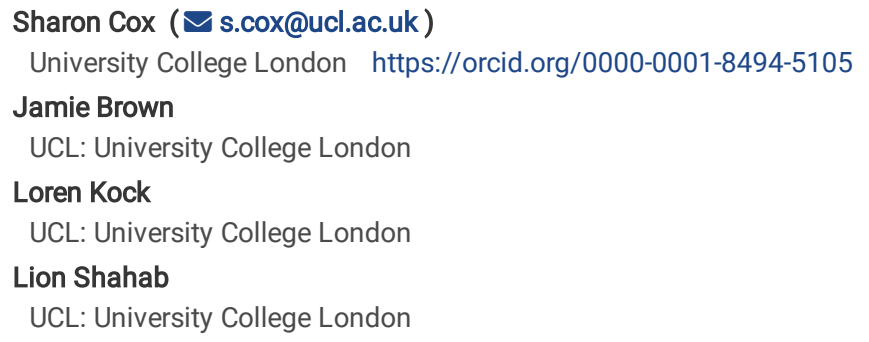

\section{Research Article}

Keywords: nicotine, e-cigarettes, tobacco cessation, non-combustible nicotine, smoking

Posted Date: April 22nd, 2021

DOI: https://doi.org/10.21203/rs.3.rs-446598/v1

License: () (1) This work is licensed under a Creative Commons Attribution 4.0 International License. Read Full License

Version of Record: A version of this preprint was published at Harm Reduction Journal on November 17th, 2021. See the published version at https://doi.org/10.1186/s12954-021-00562-9. 


\section{Abstract}

Introduction: Up-to-date monitoring of non-combustible nicotine products (NNP) is important to assess their impact. To date, there is little evidence on the association between long-term regular use (defined here as one-year or more) of NNP and current smoking status.

Aims/methods: The purpose of this study was to examine the prevalence, and sociodemographic, alcohol and smoking status correlates, of ever regular use of NNP in England in 2020.

A cross sectional survey of adults in England between February and June 2020.

Results: 8,486 adults were surveyed, $94.9 \%(8,055)$ were complete cases. The weighted prevalence of ever regular NNP use was 5.4\% ( $\mathrm{n}=436 ; 95 \% \mathrm{Cl} 5.0-6.0)$, of which $82 \%(n=360 ; 95 \% \mathrm{Cl} 78.7-85.8)$ was single, and $18 \%(\mathrm{n}=79 ; 95 \% \mathrm{Cl} 14.8-22)$ multiple product use. Amongst ever regular NNP users, the prevalence of ever regular nicotine replacement therapies (NRT), e-cigarette and heated tobacco product use was $64.7 \%(95 \% \mathrm{Cl} 60.1-69), 43.4 \%(95 \% \mathrm{Cl} 38.8-48)$ and $2.5 \%$ (95\% Cl 1.4-4.5), respectively. In regression analysis, ever regular NNP use was independently associated with smoking status, being significantly higher among current (22.3\%; Adjusted OR (aOR) 34.9, 95\% Cl 24.0-50.8) and ex-smokers (12.7\%, aOR 19.8, 95\% $\mathrm{Cl} 11.1-14.4)$ than among never smokers (0.6\%). More advantaged occupational grade (aOR, $1.2795 \% \mathrm{Cl} 1.02-1.57)$ and at least hazardous alcohol use (aOR, 1.38 95\% $\mathrm{Cl} 1.06-1.78)$ were independently associated with greater prevalence of ever regular NNP use.

Conclusions: Ever regularly using NNP was highest among smokers and ex-smokers and rare among never smokers. Among people who have ever regularly used NNP, NRT is the most popular.

\section{Introduction}

In England, e-cigarettes and a range of licensed nicotine replacement therapies (NRT) are widely available and popular. There is high and moderate certainty evidence that NRT and e-cigarettes are effective for smoking cessation (Hajek et al., 2019; Hartmann-Boyce et al., 2020; McNeill et al., 2019; National Academies of Sciences, Engineering, Medicine., (NASEM) 2018; Stead et al., 2012; Walker et al., 2020). More recently nicotine salt 'pod' e-cigarettes and heated tobacco products have also become available. The overall impact of the wide range of non-combustible nicotine products (NNP) on public health remains contested. Sources of contention include the extent to which the products are i) used by people who would not otherwise have smoked, ii) used by smokers without quitting cigarettes, and iii) able to attenuate tobacco related inequalities. Monitoring the population who report past ever regular use of NNP, for extensive periods of time, can contribute to the evidence of their likely long-term impact and how ever regular use is associated with current smoking status. The purpose of this study is to examine the prevalence of, and sociodemographic and smoking-related characteristics, associated with ever regular use (defined here as one year or more) of NNP in England in 2020.

Patterns and duration of NNP use is associated with quit success. Regular and supported use of NRT is shown to yield higher quit rates than behavioural support alone (Lindson et al., 2019; Stead et al., 2012). In England at the current time e-cigarettes are the most popular quit aid but use has been relatively stable since 2013 at approximately 5\% of the adult population (West, Beard, et al., 2020). The most recent Cochrane review of the evidence suggest that with moderate certainty e-cigarettes are more effective than other types of nicotine replacement therapies and more effective than behavioural support alone (Hartmann-Boyce et al., 2020). However, although smokers report frequent experimentation with e-cigarettes the proportion who use them regularly is much lower (Levy et al., 2018). Also, regular daily-use compared with irregular non-daily-use use by smokers is associated with a greater likelihood of smoking cessation (Hitchman et al., 2015; Levy et al., 2018). Further still, substantial health benefits are only gained when smokers switch to e-cigarettes completely (Shahab et al., 2017), and the same is also true for other nicotine products. Therefore, in order for NNP to yield the best population health benefits use of these products must result in quitting. Furthermore, unintended consequences, such as never smokers starting to use them should be minimised. At the current time, in England there is some evidence that never smokers use e-cigarettes and NRT (West, Beard et al., 2020), but the rates are extremely low, and whether this is short-term or regular use longer-term has not been clearly ascertained.

While there is a growing evidence base on the use of NRT and e-cigarettes (West, Beard, et al., 2020; Zhu et al., 2017), there is a paucity of evidence on relatively newer pod nicotine-salt e-cigarette devices (e.g. 'JUUL'), and heated-tobacco products (HTP, e.g. 'iQOS'). Monthly data from England shows very low current use of both of these products compared with 'typical' e-cigarettes and NRT (West, Beard, et al., 2020), and to date there is no data on longer-term use of these products. The relatively low cost of e-cigarette use compared with tobacco and simplicity of JUUL may be appealing to a proportion of smokers who report finding tradition tank like e-cigarettes cumbersome (Thirlway, 2016). Other smokers may find HTP appealing because they offer a similar sensory and psychological experience to smoking (Tompkins et al., 2020). However, the high start-up cost of HTP may be a barrier to initiation and regular use for those from lower income groups.

Monitoring regular ever use across NNP by sociodemographic factors and current smoking status can help to understand which groups are most likely to benefit from the wide array of products, shape public health messages and monitor unintended consequences. Early evidence showed that e-cigarettes were most likely to be used those from more advantaged social grades (Weaver et al., 2016), but a more recent analysis by Kock et al., (2019) showed that in England e-cigarette use among > 1-year ex-smokers increased among all occupational social grades from 2014 to 2017 and use was highest among those within more disadvantaged occupational social grades (Kock et al., 2019). Age is also an important factor to explore, as older adults are still more likely to choose NRT over all other products despite the growing popularity of e-cigarettes (West, Beard et al., 2020). Other substance use behaviours which are highly correlated such as alcohol are also important to explore, as substance behaviours which co-exist play a role in the use of one substance in the presence of another (Meader et al., 2016). However, co-use in this context may be more reflective of the need to use nicotine than tobacco, as evidence highlights recent exsmokers who used e-cigarettes or NRT to quit smoking consume more alcohol than those who quit unaided (Jackson et al., 2020). 
Using monthly cross-sectional data from the Smoking Toolkit Study (STS) collected between February 2020 and June 2020, this present study examined the prevalence and characteristics of ever regular use, defined here as one-year or more, of non-combustible nicotine products in England. Specifically, the following research questions were examined:

1. What is the prevalence of ever regular use of i) non-combustible nicotine products (NNP) ii) NRT, iii) E-cigarettes iv) JUUL and v) Heated-tobacco products?

2. Is ever regular use of each outcome associated with socio-demographic characteristics, smoking status and alcohol use?

\section{Methods}

\section{Design and participants}

Data was drawn from the ongoing STS, a monthly repeated cross-sectional survey of a representative sample of adults ( $\geq 16$ years) in England (Fidler et al., 2011). Each month, a form of random location in combination with quota sampling is used to select a new sample of approximately 1,700 adults aged 16 years and older. Further details on the design of the STS, including sampling and weighting technique can be found elsewhere (Fidler et al., 2011). Standard protocol means data is usually collected monthly through face-to-face computer assisted interviews. However, due to the covid-19 pandemic and rules on social distancing, from April 2020 data was collected via telephone among adults aged 18 and over only. The telephone-based data collection relied on the same combination of random location and quota sampling. For the present study we used aggregated data from the time period that the question relating to ever-regular NNP use was introduced into the survey.

\section{Measures: \\ Outcome variable}

To assess ever regular NNP use, all respondents were asked "Can I check, have you ever regularly used any of the following (i.e. for a year or more)?", responses included 1. Nicotine gum, 2. Nicotine lozenge, 3. Nicotine patch, 4. Nicotine inhaler inhalator, 5. Another nicotine product, 6 . Electronic cigarette, 7. Nicotine mouth spray, 8. Heat-not-burn cigarette (e.g. iQOS, heatsticks), 9. JUUL, 10. Other (specify). Responses for each item were coded into a binary yes/no. Product use is presented as a total of all non-combustible product use and also by category (NRT, e-cigarette, JUUL and heated tobacco products), multiple product use was calculated based on yes responses to two or more products. The addition of nicotine pouches was not included in this study as entry into the STS was after the study data collection period.

Due to a filtering error, 11 people who reported daily e-cigarette use were not asked the above question. In order to establish ever regular NNP use, the following question was used as an inclusion check, "Can I check, are you using any of the following either to help you stop smoking, to help you cut down or for any other reason at all?" and for those who said yes, a further question "How long have you been using this nicotine replacement product or these products for?", 1. Less than one week, 2 . One to six weeks, 3 . More than six weeks and up to twelve weeks, 4 . More than twelve weeks and up to 26 weeks, 5 . More than 26 weeks and up to 52 weeks, 6 . More than 52 weeks. Seven participants reported current e-cigarette use for a period of greater than 12 -weeks, were not asked about ever regular e-cigarette use, these participants were recoded as ever-regular e-cigarette users.

\section{Explanatory variables}

\section{Smoking status}

Those who reported currently smoking cigarettes or tobacco of another type were considered to be a smoker. All of those who reported having stopped smoking within the last year or before were considered ex-smokers. All others were considered never-smokers.

\section{Alcohol use}

To test the association between hazardous alcohol use across product categories, scores on the Alcohol Use Disorder Identification Test (AUDIT) were dichotomised into those scoring 8 and above or less.

\section{Socio-demographic characteristics}

For the present study we examined self-reported gender was categorized as women or other, and actual age is categorised as 16-24, 25-34, 35-44, 45-54, $55-64$, and $\geq 65$ years.

Occupation-based social grade (C2DE includes manual routine, semi-routine, lower supervisory, and long-term unemployed; ABC1 includes managerial, professional and upper supervisory occupations) and children in the household (yes/no).

Analyses: The protocol for this study was preregistered on the Open Science Framework (https://osf.io/fmypr/). Analyses were conducted using SPSS v25 on complete cases. Data was weighted to match the English population profile on age, social grade, region, tenure, ethnicity, and working status within sex and was weighted for all analyses. The dimensions are derived monthly from a combination of the English 2011 census, Office for National Statistics mid-year estimates, and an annual random probability survey conducted for the National Readership Survey. For the first research question we report the prevalence (and 95\% confidence interval [CI]) ever regular NNP use, this includes use of all NRT products, e-cigarettes and all heated tobacco products. Logistic regression estimated the association of ever regular use of each outcome with smoking status, at least hazardous drinking and sociodemographic characteristics, with and without mutual adjustment. 


\section{Results}

Across five waves from February 2020 to June 2020 a total of 8486 adults in England were surveyed and $94.9 \%$ (8055) were complete cases. The weighted prevalence of ever regular non-combustible nicotine use was $5.4 \%(n=436 ; 95 \% \mathrm{Cl} 4.9-5.9)$ of which $82.6 \%(n=360 ; 95 \% \mathrm{Cl} 78.7085 .8)$ was single and $18.1 \%$ $(n=79 ; 95 \% \mathrm{Cl} 14.8-22)$ multiple product use. Within those reporting ever product use the prevalence of ever regular NRT, e-cigarette and heated tobacco product use was $64.7 \%(n=282 ; 95 \% \mathrm{Cl} 60.1-69), 43.4 \%(n=189 ; 95 \% \mathrm{Cl} 38.8-48)$ and $2.5 \%(n=11 ; 95 \% \mathrm{Cl} 1.37-4.54)$, respectively. Ever regular use of JUUL was not reported.

Ever regular use of any NNP use was highest for current smokers $(22.3 \%, n=205 ; 95 \% \mathrm{Cl} 19.8-25.1)$, followed by ex-smokers (12.7\%, $\mathrm{n}=198 ; 95 \% \mathrm{Cl} 11.1-$ $14.4)$ with negligible use by never-smokers $(0.6 \%, \mathrm{n}=33 ; 95 \% \mathrm{Cl} 0.5-0.9)$. Ever regular use of NRT or e-cigarettes were each more prevalent in current smokers $(11 \%, \mathrm{n}=124 ; 95 \% \mathrm{Cl} 9.3-13$ and $9.3 \%, \mathrm{n}=104 ; 95 \% \mathrm{Cl} 7.7-11.1$, respectively), followed by ex-smokers $(8.2 \%, \mathrm{n}=145 ; 95 \% \mathrm{Cl} 7.1-9.6$ and $3.6 \%, \mathrm{n}=63 ; 95 \% \mathrm{Cl}$ 2.8-4.6, respectively), with very low use in never smokers $(0.2 \%, \mathrm{n}=11 ; 95 \% \mathrm{Cl} 0.1-0.4$ and $0.4 \%, \mathrm{n}=21 ; 95 \% \mathrm{Cl} 0.3-0.6$, respectively). Ever regular use of $\mathrm{HTP}$ was rare across current smokers $(0.4 \%, n=4,95 \% \mathrm{Cl} 0.1-1)$ ex-smokers $(0.2 \%, n=4,95 \% \mathrm{Cl} 0.1-0.7)$ and never-smokers $(0.1 \%, n=3,95 \% \mathrm{Cl} 0.1-0.7)$.

Table 1 presents sample characteristics of those reporting use and bivariate and multivariable associations between sociodemographic characteristics, hazardous alcohol drinking and smoking status across product categories.

Table 1 Sample descriptive characteristics and factors associated with ever past regular combined non-combustible nicotine product use (NRT, e-cigarettes and heated tobacco products combined) and NRT products, e-cigarettes 


\begin{tabular}{|c|c|c|c|c|c|c|c|c|c|c|}
\hline \multirow[b]{2}{*}{ Age } & \multirow{2}{*}{$\begin{array}{l}\text { Whole } \\
\text { sample } \\
(\mathrm{N}=8486)^{\star} \\
\%(\mathrm{n})\end{array}$} & \multicolumn{3}{|c|}{$\begin{array}{l}\text { Non-combustible nicotine products } \\
\text { combined (NNP: } \mathrm{N}=436)\end{array}$} & \multicolumn{3}{|c|}{$\begin{array}{l}\text { Nicotine Replacement Therapies (NRT: } \\
\mathrm{N}=282 \text { ) }\end{array}$} & \multicolumn{3}{|c|}{ E-cigarettes $(\mathrm{N}=189)$} \\
\hline & & $\%$ & $\begin{array}{l}\text { OR }(95 \% \mathrm{Cl}) \\
\text { p value }\end{array}$ & $\begin{array}{l}\text { Adj OR }(95 \% \\
\text { Cl) p value }\end{array}$ & $\%$ & $\begin{array}{l}\text { OR }(95 \% \mathrm{Cl}) \\
\mathrm{p} \text { value }\end{array}$ & $\begin{array}{l}\text { Adj OR }(95 \% \\
\text { Cl) p value }\end{array}$ & $\%$ & $\begin{array}{l}\text { OR }(95 \% \mathrm{Cl}) \\
\text { p value }\end{array}$ & $\begin{array}{l}\text { Adj OR (95 } \\
\% \text { Cl) p } \\
\text { value }\end{array}$ \\
\hline $16-24$ & $11.2(902)$ & 9.3 & 1 & 1 & 4.6 & 1 & 1 & 15.3 & 1 & 1 \\
\hline $25-34$ & $15.4(1240)$ & 18.9 & $\begin{array}{l}1.47(1.01- \\
2.17) 0.05\end{array}$ & $\begin{array}{l}1.33(0.87- \\
2.04) 0.19\end{array}$ & 12.4 & $\begin{array}{l}1.92(1.01- \\
3.65) 0.05\end{array}$ & $\begin{array}{l}1.66(0.83- \\
3.38) 0.15\end{array}$ & 29.1 & $\begin{array}{l}1.36(0.86- \\
2.15) 0.19\end{array}$ & $\begin{array}{l}1.22(0.79- \\
2.03) 0.46\end{array}$ \\
\hline $35-44$ & $14.7(1185)$ & 17.5 & $\begin{array}{l}1.44(0.97- \\
2.12) 0.68\end{array}$ & $\begin{array}{l}1.47(0.94- \\
2.30) 0.09\end{array}$ & 18.4 & $\begin{array}{l}3.07(1.66- \\
5.66)<0.001\end{array}$ & $\begin{array}{l}2.92(1.49- \\
5.71) 0.002\end{array}$ & 18.5 & $\begin{array}{l}0.88(0.54- \\
1.45) 0.62\end{array}$ & $\begin{array}{l}0.92(0.53- \\
1.61) 0.77\end{array}$ \\
\hline $45-54$ & $16.0(1286)$ & 17.5 & $\begin{array}{l}1.31(0.89- \\
1.94) 0.17\end{array}$ & $\begin{array}{l}1.37(0.89- \\
2.13) 0.15\end{array}$ & 20.6 & $\begin{array}{l}3.16(1.72- \\
5.80)<0.001\end{array}$ & $\begin{array}{l}3.37(1.70- \\
6.28)<0.001\end{array}$ & 13.2 & $\begin{array}{l}0.60(0.35- \\
1.02) 0.59\end{array}$ & $\begin{array}{l}0.62(0.34- \\
1.11) 0.11\end{array}$ \\
\hline $55-64$ & $14.3(1149)$ & 16.6 & $\begin{array}{l}1.39(0.94- \\
2.06) 0.10\end{array}$ & $\begin{array}{l}1.36(0.88- \\
2.13) 0.17\end{array}$ & 18.8 & $\begin{array}{l}3.23(1.75- \\
5.95)<0.001\end{array}$ & $\begin{array}{l}3.05(1.57- \\
5.90)<0.01\end{array}$ & 12.2 & $\begin{array}{l}0.61(0.35- \\
1.05) 0.74\end{array}$ & $\begin{array}{l}0.64(0.34- \\
1.14) 0.12\end{array}$ \\
\hline $65+$ & $22.8(1838)$ & 19.8 & $\begin{array}{l}1.04(0.71- \\
1.52) 0.85\end{array}$ & $\begin{array}{l}0.99(0.64- \\
1.56) 1.00\end{array}$ & 24.8 & $\begin{array}{l}2.70(1.49- \\
4.91) 0.001\end{array}$ & $\begin{array}{l}2.49(1.29- \\
4.83) 0.007\end{array}$ & 11.1 & $\begin{array}{l}0.34(0.19- \\
0.60)<0.001\end{array}$ & $\begin{array}{l}0.37(0.20- \\
0.71) 0.002\end{array}$ \\
\hline \multicolumn{11}{|l|}{ Sex } \\
\hline Male & $46.2(3720)$ & 49 & 1 & 1 & 45.7 & 1 & 1 & 58.2 & 1 & 1 \\
\hline Female & $48.4(3896)$ & 51 & $\begin{array}{l}0.92(0.76- \\
1.12) 0.40\end{array}$ & $\begin{array}{l}1.12(0.90- \\
1.37) 0.32\end{array}$ & 54.3 & $\begin{array}{l}1.15(0.91- \\
1.46) 0.25\end{array}$ & $\begin{array}{l}1.44(1.10- \\
1.86) 0.01\end{array}$ & 41.8 & $\begin{array}{l}0.69(0.51- \\
0.92) 0.69\end{array}$ & $\begin{array}{l}0.78(0.57- \\
1.07) 0.12\end{array}$ \\
\hline \multicolumn{11}{|l|}{$\begin{array}{l}\text { Social } \\
\text { grade }\end{array}$} \\
\hline C2DE & $44.5(3532)$ & 48.3 & 1 & 1 & 48.8 & 1 & 1 & 47.1 & 1 & 1 \\
\hline $\mathrm{AB} / \mathrm{C} 1$ & $55.5(4408)$ & 51.7 & $\begin{array}{l}0.85(0.70- \\
1.03) 0.11\end{array}$ & $\begin{array}{l}1.27(1.02- \\
1.57) 0.03\end{array}$ & 51.2 & $\begin{array}{l}0.84(0.66- \\
1.06) 0.14\end{array}$ & $\begin{array}{l}1.20(9.22- \\
1.55) 0.18\end{array}$ & 52.9 & $\begin{array}{l}0.90(0.67- \\
1.20) 0.46\end{array}$ & $\begin{array}{l}1.50(1.06- \\
2.01) 0.20\end{array}$ \\
\hline \multicolumn{11}{|l|}{$\begin{array}{l}\text { Children in } \\
\text { the home }\end{array}$} \\
\hline No & $66.8(5377)$ & 70.6 & 1.00 & 1.00 & 71.6 & 1.00 & 1.00 & 66.3 & 1.00 & 1.00 \\
\hline Yes & $27.8(2239)$ & 29.4 & $\begin{array}{l}0.99(0.81- \\
1.23) 0.98\end{array}$ & $\begin{array}{l}0.91(0.71- \\
1.20) 0.51\end{array}$ & 28.4 & $\begin{array}{l}1.06(0.81- \\
1.38) 0.68\end{array}$ & $\begin{array}{l}0.91(0.65- \\
1.26) 0.91\end{array}$ & 33.7 & $\begin{array}{l}0.82(0.60- \\
1.11) 0.20\end{array}$ & $\begin{array}{l}0.99(0.69- \\
1.42) 0.95\end{array}$ \\
\hline \multicolumn{11}{|l|}{$\begin{array}{l}\text { Smoking } \\
\text { status }\end{array}$} \\
\hline Never & $63.7(818)$ & 7.6 & 1 & 1 & 3.9 & 1 & 1 & 11.2 & 1 & 1 \\
\hline Ex-smoker & $19.4(1562)$ & 45.4 & $\begin{array}{l}19.81(13.63- \\
28.80)<0.001\end{array}$ & $\begin{array}{l}19.84(13.50- \\
29.15)<0.001\end{array}$ & 51.8 & $\begin{array}{l}42.45(22.89- \\
78.73)<0.001\end{array}$ & $\begin{array}{l}37.30(20.02- \\
69.49)<0.001\end{array}$ & 33.5 & $\begin{array}{l}9.02(5.49- \\
14.82) \\
<0.001\end{array}$ & $\begin{array}{l}11.25(6.71- \\
18.86) \\
<0.001\end{array}$ \\
\hline Current & 11.4 (918) & 47.7 & $\begin{array}{l}34.88(23.96- \\
50.80)<0.001\end{array}$ & $\begin{array}{l}35.34(23.96- \\
52.13)<0.001\end{array}$ & 44.3 & $\begin{array}{l}58.27(31.26- \\
108.61) \\
<0.001\end{array}$ & $\begin{array}{l}\text { 63.68(33.89- } \\
119.65) \\
<0.001\end{array}$ & 55.3 & $\begin{array}{l}24.85(15.48- \\
39.90) \\
<0.001\end{array}$ & $\begin{array}{l}23.53(14.31- \\
38.69) \\
<0.001\end{array}$ \\
\hline \multicolumn{11}{|l|}{$\begin{array}{l}\text { Hazardous } \\
\text { drinking }^{+}\end{array}$} \\
\hline No & $82.5(6541)$ & 77.5 & 1 & 1 & 78.1 & 1 & 1 & 78.6 & 1 & 1 \\
\hline Yes & $12.2(968)$ & 22.5 & $\begin{array}{l}0.51(0.40- \\
0.65)<0.001\end{array}$ & $\begin{array}{l}1.38(1.06- \\
1.78) 0.02\end{array}$ & 21.9 & $\begin{array}{l}0.54(0.40- \\
0.73)<0.001\end{array}$ & $\begin{array}{l}1.42(1.04- \\
1.95) 0.03\end{array}$ & 21.4 & $\begin{array}{l}0.56(0.39- \\
0.81) 0.002\end{array}$ & $\begin{array}{l}1.08(0.74- \\
1.58) 0.69\end{array}$ \\
\hline
\end{tabular}

Figures in bold represent statistical significance $p<0.05$

*Weighted sample so figures do not always precisely match the whole sample

${ }^{+}$Hazardous drinking as identified by scores between 8-15 on the AUDIT

In the adjusted model, being a current or ex-smoker, being of social grade (ABC1) compared with (C2DE) and at least hazardous alcohol use were significantly associated with greater prevalence of ever regular NNP use. This pattern of associations were similar for each product type with a few exceptions: the association with social grade was only observed with ever regular e-cigarette but not NRT use whereas the opposite was true for the association with at least hazardous alcohol use (Table 1). In addition, there were also some product-specific associations: older age was associated with greater odds of ever regular 
NRT use but lower odds of ever regular e-cigarette use and female sex was also independently associated with greater ever regular NRT use (Table 1). HTP ever use was low $(n=11)$ and therefore individual associations were not calculated.

\section{Discussion}

In this representative sample of adults in England ever regular use of NNP was almost entirely reported by current or ex-smokers, use of any type of nicotine product by non-smokers was minimal. Ever regular use of NRT was most prevalent, followed by e-cigarettes then heated tobacco products. Ever regular use of heated tobacco products was low and nobody in this survey reported ever regular use of the e-cigarette, JUUL.

These results extend the current literature in several ways. Firstly, it is important to monitor uptake and use of NNP across different groups including nonsmokers; the results here corroborate other surveys and reviews showing that long-term or extended use of NNP is almost exclusively linked to past or current smoking (McNeill et al., 2019). This finding is important as there have been concerns that, especially e-cigarettes, may increase the appeal of nicotine use in never smokers but there is little evidence of ever regular use reported here. Second, ever regular NRT use was more prevalent than ever regular e-cigarette use. This may in part be explained by the much greater time period over which NRT has been available to be regularly used by a much larger cohort of people who were at the time it was available current smokers.

As has been found in other UK surveys of heated tobacco products, use of these products is very low in comparison with other NNP (McNeill et al., 2018). There are several plausible explanations for this relating to accessibility of the product (limited retail outlets) and also the price of the product. As heatedtobacco products are subject to higher duty, use of the product offers little price advantage, and as has been documented elsewhere, price is a key driver for product use and motivation to quit smoking (Jackson, Shahab, et al., 2019; Thirlway, 2016). Lastly, in relation to prevalence, nobody from just over 8000 people reported ever regular use of the e-cigarette JUUL. Concerns have been raised that the 'gadgetry' and ease of use of JUUL could appeal to non-smokers, especially young non-smokers (Fadus et al., 2019), but there is no evidence of regular use reported here, even among smokers and ex-smokers. It may be that this particular brand is not as appealing in competition with other well-established types of e-cigarette brands and other types of devices, e.g., tanks or other pods, which were widely used and available on the market before the launch of JUUL, and the UK has enacted stricter regulatory control around marketing compared to the US. Differences in trends of use between the UK and the US may also be attributed to the difference in nicotine strength availability (US $59 \mathrm{mg} / \mathrm{mL}$ and UK up to $20 \mathrm{mg} / \mathrm{mL}$ ). However, monitoring trends in pod mods more broadly is useful as a number of smokers have reported not liking traditional tank devices or finding them difficult to use (Thirlway, 2016).

Use of multiple NNP was lower than single use. The design of this study means we are not able to infer cessation but if participants are using these products to quit smoking then use of a single product is potentially sub-optimal, as a recent Cochrane review of the evidence shows that use of two nicotine replacement products, fast acting combined with slow release, results in higher quit rates than single use (Lindson et al., 2019). Furthermore, a recently published randomised control trial by Walker et al., (2020) showed that use of an e-cigarette with nicotine e-liquid alongside a transdermal nicotine patch lead to modest but higher $\mathrm{CO}$ verified quit rates at 6-months compared with an e-cigarette with nicotine free e-liquid or a patch alone ( $7 \%, 4 \%$ and $2 \%$ respectively). We are also not able to assess how and in which combination the products were used. This is important future work, as the products available on the English market continue to grow, establishing which combination of products and how they are used may be most effective compared to single use is an important focus for future trials.

In relation to the sociodemographic associations, overall the results are in line with previously published work (Jackson, Hill, et al., 2019). Ever regular use of NNP was more prevalent in those from occupational grades ABC1 and use of alcohol to at least hazardous levels. Similarly, NRT was associated with female sex, older compared with younger 16-24-year-old adults and at least hazardous drinking. E-cigarettes were most commonly ever regularly used by younger adults and there is decline in use by age, again this has been reported elsewhere (Jackson, Hill, et al., 2019).

Those respondents from occupational social grades (C2DE) reported less ever regular e-cigarette use than those from more advantaged occupational grades (ABC1), but there was no social gradient effect in ever regular use of NRT. In England at the current time, smoking prevalence rates are twice as high in the least advantaged occupational grades compared with those in more advantaged professions (West, Kale, et al., 2020). Recent trial evidence has shown that ecigarettes offered within the English stop smoking services provide the best chances of quitting tobacco and remaining abstinent at one year (Hajek et al., 2019), although the impact of e-cigarettes on reducing the social gradient of tobacco use are yet to be established. Nonetheless, regular use of e-cigarettes is associated with complete switching (Hitchman et al., 2015), so how best to encourage and support those people smoking from groups with a high smoking prevalence to both initiate e-cigarette use and to use their devices more regularly to prevent relapse to smoking and reduce concurrent tobacco use requires more consideration.

There is conflicting evidence on the use NNP (Smith et al., 2015), but here females report higher use of NRT. Evidence from across health sciences show men often require more encouragement to engage in formal health promoting interventions (Robertson et al., 2008). We also found an inverse association with age; this is not surprising given that these products have been widely available for a longer period of time. However, speculatively e-cigarettes may be more appealing to younger users than NRT and this could also reflect a diffusion of technology e.g., older smokers adopt e-cigarette use at a reduced pace compared with younger smokers. Lastly, in line with our recent work, a higher level of self-reported alcohol use was associated with NNP use and NRT (Jackson et al., 2020). This may indicate that users who are more nicotine dependent are more likely to drink alcohol. This may signal that for those smokers who drink alcohol regularly additional support is required to stop smoking and specifically tailored support to help them in situations when they are consuming alcohol and or they cannot smoke (i.e. for temporary abstinence).

This study offers a useful understanding of which groups are using NNP and how ever-regular use of one year or more is associated with current smoking status; however, there are some limitations. No causal or temporal associations with cessation can be made as this analysis is cross sectional only and we have not reported here why people were using these products, but this does lead to important questions for future research. We inferred a small sample $(n=7)$,

Page 6/9 
of people currently using e-cigarettes were regular users - and therefore ever regular users - if they reported using products for more than 12 weeks (beyond standard length of time products are used for smoking cessation). Other limitations include potential recall bias, that is self-reporting is not always accurate, and regular use may be considered differently across individuals, future research should try to capture more granular patterns of use although this may be hard over more sustained periods of time. Our data was collected during the early part of the covid-19 pandemic in England, this may have impacted the sample or nature of information provided as respondents were interviewed by telephone instead of face-to-face.

Future studies should try to gain a more detailed pattern of regular use, especially key differences in the trajectory of ever regular use between current smokers, ex-smokers and dual users. That is, understanding how usage patterns, frequency and duration, are associated with helping people quit tobacco and remain quit. Furthermore, a high proportion of smokers report regularly using NRT and e-cigarettes, what is not known is whether these individuals reached a period of abstinence and then relapsed or whether they relapsed back to smoking. We observed clear effects of ever regular product use by age, and future research could focus on the distinct needs of older versus younger smokers, including whether e-cigarettes are not appealing to older smokers or whether lower uptake reflects products diffusion, or both. Lastly, there has been an increase in the number of smokers attempting to quit during the covid-19 pandemic ${ }^{1}$, but also increased stress and uncertainty, so while smokers may be attempting to use NNP how this transfers into longer-term use over this unique period will require further monitoring.

\section{Conclusion}

To conclude, regular NNP use of one-year or more is associated with current smoking or ex-smoking and we report little use amongst never-smokers, this is an important finding as with the rise of NNP there has been concerns raised regarding use by never-smokers. If never-smokers are using these products, then it does not appear to be habit forming. It therefore remains the case that non-combustible nicotine research should focus on how best to help people who smoke to quit. However, NNP use was also independently associated with more advantaged occupational grades and given the large burden of smoking on health inequalities how best to support smokers from less advantaged positions to switch to safer forms of nicotine and stay switched remains an important focus for future work.

\section{Abbreviations}

NNP: Non-combustible nicotine product/s

NRT: Nicotine replacement therapies

E-cigarette: electronic cigarette

\section{Declarations}

\section{Author declarations}

\section{Ethics approval and consent to participate}

Ethical approval for the STS is granted by the UCL Ethics Committee (ID 0498/001). The data is not collected by UCL and is anonymised when received by the research team.

\section{Consent for publication}

All authors agree to the submission of this manuscript and we can confirm that the findings have not been published nor under consideration at any other journal.

\section{Availability of data and materials}

The protocol for this study can be found at Open Science Framework (https://osf.io/fmypr/). The data output will be available at this page after publication.

\section{Competing interests}

$\mathrm{SC}$ has provided expert consultancy to providers of UK life insurance and to the pharmaceutical industry relating to the development of smoking cessation aids. JB has received unrestricted research funding to study smoking cessation from companies who manufacture smoking cessation medications. LK has no competing interests to declare. LS has received a research grant and honoraria for a talk and travel expenses from manufacturers of smoking cessation medications (Pfizer and Johnson \& Johnson).

\section{Funding}

This work is funded by Cancer Research UK (C1417/A22962) and salary for SC and JB. Contributions

SC, JB and LS conceptualised the study. SC and LS completed the data analysis. SC wrote the first draft of the manuscript. JB,LK, LS all contributed to the writing of final manuscript.

\section{Acknowledgements}




\section{References}

1. Fadus MC, Smith TT, Squeglia LM. The rise of e-cigarettes, pod mod devices, and JUUL among youth: Factors influencing use, health implications, and downstream effects. Drug Alcohol Depend. 2019;201:85-93. https://doi.org/10.1016/j.drugalcdep.2019.04.011.

2. Fidler JA, Shahab L, West O, Jarvis MJ, McEwen A, Stapleton JA, Vangeli E, West R. 'The smoking toolkit study': A national study of smoking and smoking cessation in England. BMC Public Health. 2011;11(1):479. https://doi.org/10.1186/1471-2458-11-479.

3. Hajek P, Phillips-Waller A, Przulj D, Pesola F, Myers Smith K, Bisal N, Li J, Parrott S, Sasieni P, Dawkins L, Ross L, Goniewicz M, Wu Q, McRobbie HJ. A Randomized Trial of E-Cigarettes versus Nicotine-Replacement Therapy. N Engl J Med. 2019;380(7):629-37. https://doi.org/10.1056/NEJMoa1808779.

4. Hartmann-Boyce J, McRobbie H, Lindson N, Bullen C, Begh R, Theodoulou A, Notley C, Rigotti NA, Turner T, Butler AR, Hajek P. Electronic cigarettes for smoking cessation. Cochrane Database of Systematic Reviews. 2020. https://doi.org/10.1002/14651858.CD010216.pub4.

5. Hitchman SC, Brose LS, Brown J, Robson D, McNeill A. Associations Between E-Cigarette Type, Frequency of Use, and Quitting Smoking: Findings From a Longitudinal Online Panel Survey in Great Britain. Nicotine Tob Res. 2015;17(10):1187-94. https://doi.org/10.1093/ntr/ntv078.

6. Jackson SE, Beard E, Michie S, West R, Brown J. Is the use of e-cigarettes for smoking cessation associated with alcohol consumption? A population-level survey of successful quitters in England. Addict Behav. 2020;101:106138. https://doi.org/10.1016/j.addbeh.2019.106138.

7. Jackson SE, Hill E, Shahab L, Beard E, Michie S, Brown J. Prevalence and correlates of long-term e-cigarette and nicotine replacement therapy use: A prospective study in England. BMJ Open. 2019;9(10):e029252. https://doi.org/10.1136/bmjopen-2019-029252.

8. Jackson SE, Shahab L, Kock L, West R, Brown J. Expenditure on smoking and alternative nicotine delivery products: A population survey in England. Addiction. 2019;114(11):2026-36. https://doi.org/10.1111/add.14709.

9. Kock L, Shahab L, West R, Brown J. E-cigarette use in England 2014-17 as a function of socio-economic profile: E-cigarette use by socio-economic status. Addiction. 2019;114(2):294-303. https://doi.org/10.1111/add.14446.

10. Levy DT, Yuan Z, Luo Y, Abrams DB. The Relationship of E-Cigarette Use to Cigarette Quit Attempts and Cessation: Insights From a Large, Nationally Representative U.S. Survey. Nicotine Tob Res. 2018;20(8):931-9. https://doi.org/10.1093/ntr/ntx166.

11. Lindson N, Chepkin SC, Ye W, Fanshawe TR, Bullen C, Hartmann-Boyce J. Different doses, durations and modes of delivery of nicotine replacement therapy for smoking cessation. Cochrane Database of Systematic Reviews. 2019. https://doi.org/10.1002/14651858.CD013308.

12. McNeill A, Brose L, Calder R, Bauld L, Robson D. (2018). Evidence review of e-cigarettes and heated tobacco products 2018. A report commissioned by Public Health England. Public Health England. https://www.gov.uk/government/publications/e-cigarettes-and-heated-tobacco-products-evidencereview/evidence-review-of-e-cigarettes-and-heated-tobacco-products-2018-executive-summary\#authors-and-citation.

13. McNeill A, Brose L, Calder R, Bauld L, Robson D. (2019). Vaping in England: An evidence update, February 2019. A report commissioned by Public Health England.

https://assets.publishing.service.gov.uk/government/uploads/system/uploads/attachment_data/file/821179/Vaping_in_England_an_evidence_update_F

14. Meader N, King K, Moe-Byrne T, Wright K, Graham H, Petticrew M, Power C, White M, Sowden AJ. A systematic review on the clustering and co-occurrence of multiple risk behaviours. BMC Public Health. 2016;16(1):657. https://doi.org/10.1186/s12889-016-3373-6.

15. National Academies of Sciences, Engineering, and Medicine. Public health consequences of e-cigarettes. (2018). National Academies Press.

16. Robertson LM, Douglas F, Ludbrook A, Reid G, van Teijlingen E. What works with men? A systematic review of health promoting interventions targeting men. BMC Health Services Research. 2008;8(1):141. https://doi.org/10.1186/1472-6963-8-141.

17. Shahab L, Goniewicz ML, Blount BC, Brown J, McNeill A, Alwis KU, Feng J, Wang L, West R. Nicotine, Carcinogen, and Toxin Exposure in Long-Term ECigarette and Nicotine Replacement Therapy Users: A Cross-sectional Study. Ann Intern Med. 2017;166(6):390. https://doi.org/10.7326/M16-1107.

18. Smith PH, Kasza KA, Hyland A, Fong GT, Borland R, Brady K, Carpenter MJ, Hartwell K, Cummings KM, McKee SA. Gender Differences in Medication Use and Cigarette Smoking Cessation: Results From the International Tobacco Control Four Country Survey. Nicotine Tob Res. 2015;17(4):463-72. https://doi.org/10.1093/ntr/ntu212.

19. Stead LF, Perera R, Bullen C, Mant D, Hartmann-Boyce J, Cahill K, Lancaster T. Nicotine replacement therapy for smoking cessation. Cochrane Database of Systematic Reviews. 2012. https://doi.org/10.1002/14651858.CD000146.pub4.

20. Thirlway F. Everyday tactics in local moral worlds: E-cigarette practices in a working-class area of the UK. Soc Sci Med. 2016;170:106-13. https://doi.org/10.1016/j.socscimed.2016.10.012.

21. Tompkins CNE, Burnley A, McNeill A, Hitchman SC. (2020). Factors that influence smokers' and ex-smokers' use of IQOS: A qualitative study of IQOS users and ex-users in the UK. Tobacco Control, tobaccocontrol-2019-055306. https://doi.org/10.1136/tobaccocontrol-2019-055306.

22. Use of e-cigarettes (vaporisers) among adults in Great Britain 2019. (2019). Action on Smoking and Health. https://ash.org.uk/wpcontent/uploads/2019/09/Use-of-e-cigarettes-among-adults-2019.pdf.

23. Walker N, Parag V, Verbiest M, Laking G, Laugesen M, Bullen C. Nicotine patches used in combination with e-cigarettes (with and without nicotine) for smoking cessation: A pragmatic, randomised trial. The Lancet Respiratory Medicine. 2020;8(1):54-64. https://doi.org/10.1016/S2213-2600(19)30269-3.

24. Weaver SR, Majeed BA, Pechacek TF, Nyman AL, Gregory KR, Eriksen MP. Use of electronic nicotine delivery systems and other tobacco products among USA adults, 2014: Results from a national survey. International Journal of Public Health. 2016;61(2):177-88. https://doi.org/10.1007/s00038-015-07610 . 
25. West R, Beard, Emma, Kale D, Jamie Brown. Trends in electronic cigarette use in England. Update 3rd July 2020. Smoking Toolkit Study; 2020. http://www.smokinginengland.info.

26. West R, Kale D, Brown J. Monthly trends on smoking in England from the Smoking Toolkit Study. The Smoking Toolkit Study; 2020. http://www.smokinginengland.info/latest-statistics/.

27. Zhu S-H, Zhuang Y-L, Wong S, Cummins SE, Tedeschi GJ. (2017). E-cigarette use and associated changes in population smoking cessation: Evidence from US current population surveys. BMJ, j3262. https://doi.org/10.1136/bmj.j3262. 